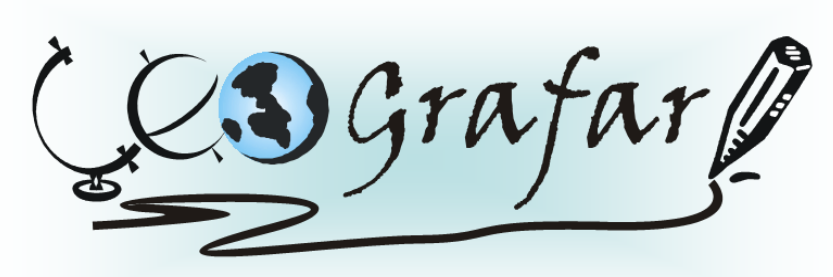

Revista Eletrônica do Programa de Pós-Graduação em Geografia - UFPR

\title{
A LEITURA DO MUNDO E O ENSINO DE GEOGRAFIA: A DOCÊNCIA EM $\mathrm{FOCO}^{1}$
}

\author{
WORLD READING AND GEOGRAPHY EDUCATION: TEACHING IN FOCUS
}

(Recebido em 25-09-2017; Aceito em: 31-01-2018)

Samara Mirelly da Silva Mestre em Geografia pelo Programa de Pós Graduação em Geografia da Universidade Federal de São João Del-Rei samaramirelly.silva@gmail.com

Vicente de Paula Leão Doutor em Geografia, Professor da Universidade Federal de São João Del-Rei leaogeo@ufsj.edu.br

\begin{abstract}
Resumo
A formação docente e 0 ensino de Geografia nos Anos Iniciais do Ensino Fundamental (AIEF) são 0 cerne das discussões presentes neste artigo. A leitura da palavra-mundo anunciada por Paulo Freire, apresenta-se como possibilidade entre a leitura do espaço da vida e a alfabetização. Logo, o diálogo entre esta e o conhecimento geográfico, exige dos professores clareza teórico-metodológica. Contudo, o modo com que os cursos de Pedagogia, responsáveis pela formação inicial dos docentes dos AIEF, contemplam as áreas específicas nem sempre os fazem cumprir satisfatoriamente com seus objetivos. Concomitantemente, em um mundo altamente plural, complexo e dinâmico, não se pode ignorar a formação permanente e a atitude de professor- pesquisador como feitios essenciais à práxis docente. Considera-se, desse modo, que a formação dos professores (inicial e continuada) tem papel salutar na promoção da leitura da palavra-mundo nessa etapa da escolarização, e por isto, são o alicerce da presente incursão teórica.
\end{abstract}

Palavras-chave: Formação docente. Prática docente. Geografia. Leitura palavra-mundo.

\begin{abstract}
Teacher training and the teaching of Geography in the Early Years of Elementary Education (EYEE) are the core of the discussions in this article. The reading of the world word announced by Paulo Freire, presents itself as a possibility between reading the space of life and literacy. Therefore, the dialogue between this and the geographic knowledge, demands from the teachers theoretical-methodological clarity. However, the way in which
\end{abstract}

\footnotetext{
${ }^{1}$ Este texto é baseado na pesquisa de mestrado "A presença dos conceitos estruturadores do conhecimento geográfico nos Cursos de Pedagogia em Minas Gerais", concluída no ano de 2017 e desenvolvida no âmbito do Programa de Pós Graduação em Geografia da Universidade Federal de São João del-Rei (PPGeog/UFSJ), por Samara Mirelly da Silva e orientada por Vicente de Paula Leão.
} 


\section{A LEITURA DO MUNDO E O ENSINO DE GEOGRAFIA: A DOCÊNCIA EM FOCO}

the Pedagogy courses, which are responsible for the initial training of the AIEF teachers, contemplate the specific areas do not always make them fulfill their objectives satisfactorily. Concurrently, in a highly plural, complex and dynamic world, one can not ignore the permanent formation and the attitude of teacher-researcher as essential characteristics of teacher praxis. Thus, it is considered that teacher training (initial and continued) has a salutary role in promoting the reading of the world word at this stage of schooling.

Keywords: Teacher training. Teaching practice. Geography. Read word-world.

\section{Introdução}

Em A importância do ato de ler (1989), Paulo Freire afirma que "a leitura do mundo precede a leitura da palavra". Entretanto, esta não é apenas precedida, mas representa certa forma de escrevê-lo, ou de "transformá-lo através de nossa prática consciente" (Ibidem: 20).

O educador (1989) enfatiza, ainda, que o movimento dinâmico do mundo à palavra e da palavra ao mundo deve não só estar presente, mas ser um dos aspectos centrais na alfabetização. Por consequência, a compreensão do contexto do texto em uma relação dinâmica que vincula realidade e linguagem transcende a decodificação mecânica de palavras vazias e ocas de significação (idem, 1996). Assim, o respeito ao contexto cultural dos alunos se torna substancial, ao passo que "A localidade dos educandos é o ponto de partida para o conhecimento que eles vão criando do mundo. 'Seu' mundo, em última análise, é a primeira e inevitável face do mundo mesmo" (FREIRE, 1992: 86).

Por estas e tantas outras questões que poderiam aqui serem elencadas, que se reforça a necessidade de um ensino significativo de Geografia, passível de ser inserido no processo de alfabetização das crianças e consequentemente, de alimentar a leitura da palavra-mundo no transcorrer nos Anos Iniciais do Ensino Fundamental (AIEF).

Cabe considerar, no entanto e de imediato, que não se espera, ou mesmo se pretende incentivar uma tirania científica, (em que determinada área do conhecimento seja considerada mais respeitável que outra, no caso, a de Geografia superior à Ciências, História, Arte, etc.), o que se discute é a importância de um trabalho interdisciplinar que valorize as diferentes áreas do conhecimento presentes nos programas escolares. Afim que estas contribuam de fato, para uma formação cidadã, crítica e transformadora da sociedade² iniciada ainda nos AIEF (SILVA, LEÃO, 2016). Tendo em vista que, muitas vezes, o ensino de Geografia presente nessa etapa da escolarização não contribui para o desenvolvimento da criticidade e do sentimento de pertencimento e cidadania, que nos fala Freire (2003) e os Parâmetros Curriculares Nacionais de Geografia para os Ciclos Iniciais (PCN) (BRASIL, 1997).

\footnotetext{
${ }^{2}$ Para Paulo Freire, a educação é um ato político. Nas palavras do autor, "(...) foi por isso que eu falei na natureza política da educação como uma totalidade, e da alfabetização como um capítulo dela. A alfabetização em si não é sequer o começo da cidadania, mas a experiência cidadã requer a alfabetização" (FREIRE, 2001: 131).
} 


\section{A LEITURA DO MUNDO E O ENSINO DE GEOGRAFIA: A DOCÊNCIA EM FOCO}

Desta forma, ao se refletir sobre as possibilidades do ensino de Geografia (alfabetização geográfica) versar para a leitura do espaço, do mundo da vida e da consequente, leitura da palavramundo nos AIEF, como pode, por vezes, este não despertar interesse nos educandos?

Dentre as inúmeras perspectivas de análise possíveis, uma nos chama atenção e será mais aprofundada ao decorrer deste texto: A formação docente. Entende-se que o modo com que os cursos de Pedagogia, responsáveis pela formação inicial dos professores dos AIEF, contemplam as áreas específicas nem sempre os fazem cumprir satisfatoriamente com seus objetivos, embora estas posições e direcionamentos afetem diretamente a qualidade do ensino na escola básica.

Contudo, em um mundo altamente plural, complexo e dinâmico, não podemos ignorar a importância da formação permanente e a atitude de professor- pesquisador para práxis docente, sobretudo, para aqueles comprometidos com a Educação Básica e com a aprendizagem significativa de seus alunos. Afinal, é necessário entender os professores como sujeitos também ativos no processo de ensino e aprendizagem, que possuem/desenvolvem um saber-fazer próprio ao longo de suas carreiras (TARDIF, 2000).

\section{Geografia Escolar e a Leitura da Palavra-Mundo}

Apesar das especificidades da Geografia acadêmica e da Geografia escolar, entende-se que a segunda deve ser fundamentada em bases científicas. Assim, o ensino de Geografia mesmo nos AIEF deve ser realizado à luz dos conceitos e linguagens próprios deste ramo da ciência. Segundo Helena C. Callai (2011: 131), a Geografia se constrói como disciplina escolar (resumidamente) na referência: Ida academia, como ciência com seu aporte teórico, metodológico, de investigação e linguagem própria; II- do contexto dos lugares, o trabalho com o currículo escolar, demarcado pelos conteúdos curriculares escolares e pelas políticas públicas que o orientam e, concomitantemente, pelas pessoas que fazem parte deste processo.

O ensino de Geografia na Educação Básica pode ter como pressuposto a promoção de uma educação voltada para a formação de sujeitos autônomos, conscientes, críticos e reflexivos sobre o real. Para isto, é oportuno que os educandos tenham acesso aos conceitos, procedimentos e linguagem própria do conhecimento geográfico. Nesse sentido, Rafael Straforini ao discutir o ensino da totalidade-mundo nos Anos Iniciais do Ensino Fundamental, afirma:

Não se espera que uma criança de sete anos possa compreender toda a complexidade das relações do mundo com o seu lugar de convívio e vice-versa. No entanto, privá-la de estabelecer hipóteses, observar, descrever, representar e construir suas explicações é uma prática que não condiz mais com o mundo atual e uma Educação voltada para a cidadania (2001: 56-57). 
A intercessão da Geografia escolar com o espaço cotidiano dos alunos por meio da observação, descrição e análise pode levar as crianças a identificarem e refletirem sobre as paisagens que Ihes são familiares. Entretanto, é necessário trabalhar com diferentes escalas de análise (local, nacional, global) uma vez que elas se inter-relacionam e conectam, oportunizando uma leitura mais crítica dos alunos quanto aos espaços vividos, percebidos e concebidos.

Assim, "Ler o mundo da vida, ler o espaço e compreender as paisagens que vemos como resultado da vida em sociedade [...], esse é o papel da Geografia escolar" (CALLAI, 2013: 228-229). Em uma educação preocupada com a promoção da criticização dos sujeitos e do despertar de suas consciências enquanto atores sociais produtores de cultura e participantes ativos da construção de suas realidades, não se pode ignorar nesse ensino, todavia, a produção desigual desses espaços e a atuação de seus diferentes atores.

Destacadamente, é partindo do lugar, considerando a realidade concreta do espaço vivido, no cotidiano da própria vivência que as coisas vão acontecendo e, dessa maneira, configurando o espaço, dando feição ao lugar (idem, 2005, 2014). Nesse contexto, cabe aos educadores procurar desenvolver nos alunos uma atitude de agentes responsáveis pela construção de ambientes, mas como atuantes, cada um a seu modo, nessa construção (CAVALCANTI, 2002: 43).

Conforme Antônio Carlos Castrogiovanni (2009), o espaço geográfico e suas multidimensões compreendem todas as estruturas e formas de organização e interações. É, portanto, segundo 0 autor, tudo e todos. "A compreensão da formação de grupos sociais, a diversidade social e cultural, assim como a apropriação da natureza por parte dos homens, deve fazer parte também dessa alfabetização [geográfica nas Séries Iniciais]" (Ibidem: 12).

0 processo de aquisição do conhecimento geográfico na Educação Básica passa pelo reconhecimento de que, "ao criar o espaço, [a sociedade] reproduz a si mesma" (LEÃO, 2008: 85). Dessa feita, é salutar, nessa intervenção, a consideração dos processos naturais, as escalas espaçotemporais e a leitura de mundo dos educandos, conforme ilustra o esquema proposto por Janine Le Sann e Roberto C. Valadão (2003). 
Figura 1 - 0 processo de aquisição do conhecimento geográfico

\section{O processo de aquisição do conhecimento geográfico:} "Da Geografia à Representação do Espaço Geográfico"
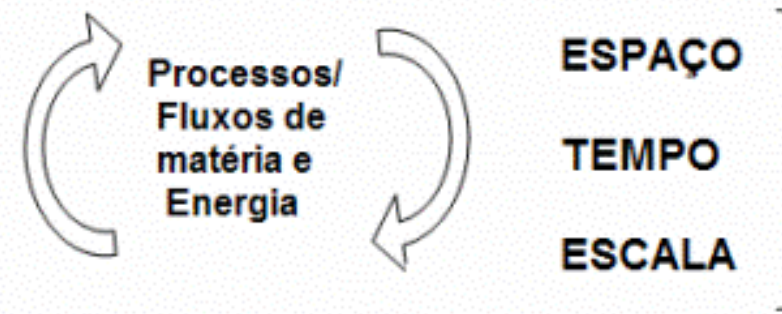

ESCALA

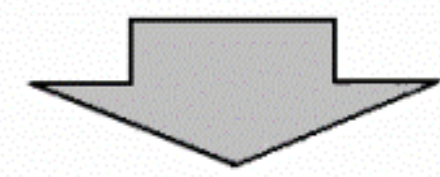

"O Sujeito / 0 aluno" (imagem mental; percepção; experiência de vida;

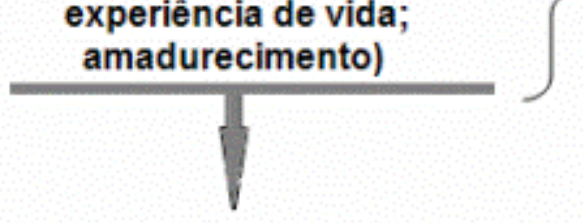

"Leitura de Mundo" REPRESENTAÇÃO

Fonte: Le Sann e Valadão (2003: s/p).

Logo, o espaço é, portanto, o mediador do processo de reprodução da sociedade (LEÃO, 2008) e sua representação e estudo, passa também pela Leitura de Mundo dos alunos. Consequentemente, busca-se realçar o cuidado que o ensino e aprendizagem de Geografia merece desde os anos iniciais para que os alunos se sintam de fato "membros participantes, afetivamente ligados, responsáveis e comprometidos historicamente" (BRASIL, 1997: 76) com o espaço em que vivem. Para que, consequentemente, envolvidos com o espaço geográfico em sua constante (re)construção, em um mundo de possibilidades, e não de fatalismos (FREIRE, 1996), o compreendam como um espaço de contradições, mas, também, de transformações.

Desta forma, espera-se que o estudo do espaço geográfico possa ser trabalhado desde o início da escolarização. Todavia, não aquele inerte, linear, fragmentado, inativo, mas o objeto de estudo em Geografia, ou seja, o "nosso" espaço, fruto das relações sociais e da interação entre sociedades e natureza. Nesse sentido, os professores devem criar condições que favoreçam diferentes estratégias cognitivas e ritmos de aprendizagem, a fim de que os educandos evoluam dos conceitos prévios aos 
raciocínios mais complexos, com postura ética e de comprometimento coletivo (CASTROGIOVANNI, 2009: 8).

Isso posto, o estudo das categorias de análise da Geografia se inserem nesse contexto. Estudar o lugar, por exemplo, pode ser interessante por dois motivos, de acordo com Callai (2005), primeiro, porque mesmo em um mundo globalizado, as ideias universais se concretizam nos lugares e depois, dessa forma, se pode perceber que, há possibilidade de não ser apenas cobaias ou partes de uma estrutura na qual não têm o direito de pensar e de tomar outras atitudes que pareçam mais adequadas. "Ao se reconhecer o lugar como parte de nossa vida, como um dado que nos permite criar uma identidade e termos a ideia de pertencimento, será possível agir para o grupo, e não apenas para servir a interesses externos" (Ibidem: 242).

Consequentemente, uma vez que as crianças são coprodutoras de espaços e tempos sociais, evidencia-se a importância de se considerar o espaço vivido por elas nas aulas de Geografia, sobretudo nos AIEF;

Essa capacidade de interlocução (de saber ouvir, falar, observar, analisar, compreender) pode ser desenvolvida desde a educação infantil e tornar-se assim um método de estudo - de fazer a leitura do mundo. Ao partir da vivência concreta, busca-se a ampliação do espaço da criança com a aprendizagem da leitura desses espaços e, como recurso, desenvolve-se a capacidade de 'aprender a pensar o espaço', desenvolvendo raciocínios geográficos, incorporando habilidades e construindo conceitos (Ibidem: 235).

A capacidade de "pensar o espaço" a partir da leitura que dele se faz se torna preponderante ao ensino crítico que verse para a cidadania, no entendimento e enfrentamento dos problemas e questões postas à vida individual das pessoas e enquanto pertencentes a uma coletividade.

Nesse sentido, Freire (1989) ressalta a importância da leitura da palavra-mundo no processo de alfabetização e da necessidade de se trabalhar com palavras grávidas do universo vocabular dos educandos e não dos educadores, sobretudo na educação de jovens e adultos ${ }^{3}$. Ao revisitar em suas memórias, como foi se constituindo a importância do ato de ler ao decorrer de sua existência, o educador narra sua relação ainda na infância, com o meio em que vivia, as árvores, animais e pessoas. E como foi introduzido na leitura da palavra;

A decifração da palavra fluía naturalmente da 'leitura' do mundo particular. Não era algo que se estivesse dado superpostamente a ele. Fui alfabetizado no chão do

\footnotetext{
${ }^{3}$ Paulo Freire (1921-1997), lutou pela educação conscientizadora e alfabetização, sobretudo, política de jovens e adultos das classes desfavorecidas, pois, segundo o próprio, seu ponto de vista era o dos esfarrapados do mundo, os "condenados da Terra", o ponto de vista dos excluídos.
} 


\section{A LEITURA DO MUNDO E O ENSINO DE GEOGRAFIA: A DOCÊNCIA EM FOCO}

quintal de minha casa, à sombra das mangueiras com palavras do meu mundo e não do mundo maior dos meus pais. 0 chão foi meu quadro-negro; gravetos, o meu giz (Ibidem: 15).

Destarte, entende "A alfabetização como ato de conhecimento, como ato criador e como ato político é um esforço de leitura do mundo e da palavra (ibidem: 30). Em que a palavra dita flui do mundo através da leitura que dele fazemos e volta ao mundo com maior criticidade.

Desta forma, ao considerar nos AIEF, a relação entre leitura da palavra-mundo e a compreensão do espaço geográfico como um possível ponto de encontro entre a alfabetização e o ensino de Geografia percebe-se a relevância de uma atuação docente comprometida com um projeto de transformação social, vinculado às linguagens, métodos e conceitos próprios do conhecimento geográfico.

Assim, o ensino de Geografia (crítico e significativo) a partir da leitura do mundo, como método de aprender a pensar o espaço (CALLAI, 2005), se torna uma importante ferramenta durante a alfabetização, sobretudo em uma escola preocupada com a promoção da criticização dos sujeitos e à promoção da cidadania.

Pelo exposto, e ainda considerando o espaço geográfico (que é social e histórico) o objeto de estudo de estudo da Geografia e as categorias de análise (lugar, paisagem, território) - como àquelas adequadas de serem trabalhadas nos ciclos iniciais, segundo os Parâmetros Curriculares Nacionais de Geografia (BRASIL, 1997), nos vem algumas inquietações como: Por que, ainda assim, 0 conhecimento geográfico, muitas vezes, não é atrativo aos alunos dos AIEF?

Volta-se deste modo, à atuação docente, mais especificamente à sua formação, um dos aspectos fundamentais da educação formal. Compreender como os professores são formados para lecionar Geografia nessa etapa, pode de certa forma, fazer referência às opções teóricas e metodológicas adotadas em suas práticas. Nesse sentido, podem igualmente fornecer indícios quanto a presença/ausência do conhecimento geográfico nos AIEF. Tendo em vista que, conforme Callai (2005: 231), a clareza teórico-metodológica é basilar "para que o professor possa contextualizar os seus saberes, dos alunos e do mundo a sua volta".

\section{A formação de professores para o Ensino Fundamental no Brasil}

A formação dos profissionais para lecionarem na Educação Infantil, bem como nos primeiros ciclos do Ensino Fundamental na década de 1990, poderia se dar, segundo a Lei de Diretrizes e Bases da Educação Nacional (LDB, Lei n 9.394/96) (BRASIL, 1996), em dois lugares: no curso Normal 
Superior, dentro dos Institutos Superiores de Educação (ISE), e no curso de Pedagogia, em Universidades e Centros Universitários.

Entre as atribuições conferidas aos ISE, competiam a manutenção dos cursos formadores dos profissionais para a Educação Básica, inclusive o curso Normal Superior (destinado à formação docente para a educação infantil e AIEF), os programas de formação pedagógica para portadores de diplomas que pretendiam se dedicar à Educação Básica e os programas de educação continuada para os profissionais de educação dos diversos níveis (BRASIL, 1996).

O Projeto Político Pedagógico do Curso (PPC) de Pedagogia, modalidade presencial da Universidade Federal de Alfenas (PPC Pedagogia, UNIFAL, 2011), afere a esse respeito que 0 questionamento principal a esse tocante foi a descaracterização do curso de Pedagogia enquanto Licenciatura e a tentativa de colocá-lo como um Bacharelado, uma vez que a legislação determinava que os professores para a Educação Básica fossem formados, preferencialmente, nos ISE, pelo curso Normal Superior.

A respeito dos cursos de Pedagogia, a LDB, em seu Artigo 64, determinava que

A formação de profissionais de educação para administração, planejamento, inspeção, supervisão e orientação educacional para a educação básica será feita em cursos de graduação em pedagogia ou em nível de pós-graduação, a critério da instituição de ensino, garantida, nesta formação, a base comum nacional (BRASIL, 1996).

Configura-se, dessa maneira, um paradoxo na LDB no 9.394/96 e nos seus documentos normatizadores. De um lado, cria os Institutos Superiores de Educação (Resolução $n^{0} 1 / 99$ ), define o Curso Normal Superior como espaço preferencial para a formação dos professores da Educação Básica (Decreto $n^{0} 3.554 / 2000$ ) e, de outro, preserva esta função ao curso de Pedagogia (Art. 62 da LDB n 9.394/96), tendo, como consequência, dois cursos em espaços distintos, com a mesma atribuição acadêmica. Por isso, o tocante ao curso de Pedagogia na LDB $n^{0}$ 9.394/96 apresenta ambiguidades, o que permite interpretações diferenciadas (PPC PEDAGOGIA, UNIFAL, 2011: 22).

De acordo com o PPC de Pedagogia da Universidade Federal de Uberlândia (FACIP/UFU) (2007: 11), criaram-se ambiguidades, pois se configuravam em dois espaços diferentes, com concepções distintas, abrigando a mesma formação, "Contradições que impedem e impediram até então a confirmação do perfil dos profissionais da educação no Brasil".

Após reinvindicações e negociações entre os diversos atores em cena na discussão das políticas de formação de profissionais da educação (entre eles a ANFOPE4) para que os cursos de Pedagogia tivessem suas próprias Diretrizes (SCHEIBE, 2008), em 16 de maio de 2006, foi publicada,

${ }^{4}$ Associação Nacional pela Formação dos Profissionais da Educação 


\section{A LEITURA DO MUNDO E O ENSINO DE GEOGRAFIA: A DOCÊNCIA EM FOCO}

no Diário Oficial da União, a Resolução CNE/CP no 1 (BRASIL, 2006), que institui as Diretrizes Curriculares Nacionais para o Curso de Graduação em Pedagogia, licenciatura 5 .

Essa publicação mostra a tentativa de colocar à docência como a base profissional do pedagogo, consequentemente devolvendo aos cursos superiores de Pedagogia a responsabilidade pela formação dos profissionais que atuarão na Educação Infantil e Anos Iniciais do Ensino Fundamental.

A docência, por conseguinte, é tida como fundamento da formação do pedagogo, apreendida nas Diretrizes Curriculares Nacionais para o Curso de Pedagogia, licenciatura, como:

$\S 1^{0}[. .$.$] ação educativa e processo pedagógico metódico e intencional, construído$ em relações sociais, étnico-raciais e produtivas, as quais influenciam conceitos, princípios e objetivos da Pedagogia, desenvolvendo-se na articulação entre conhecimentos científicos e culturais, valores éticos e estéticos inerentes a processos de aprendizagem, de socialização e de construção do conhecimento, no âmbito do diálogo entre diferentes visões de mundo (BRASIL, 2006).

Nesse contexto, ainda segundo as Diretrizes, os cursos de Pedagogia devem dedicar-se à formação docente para ambientes escolares e não escolares onde sejam previstos os conhecimentos pedagógicos, o que se constituirá em pluralidade de conhecimentos teóricos e práticos.

\section{Os cursos de Pedagogia e a formação nas áreas específicas, em especial, a Geografia}

A despeito da formação de professores nos cursos de Pedagogia, Gatti e Nunes (2009), organizadoras do estudo Formação de professores para o ensino fundamental: estudo de currículos das licenciaturas em Pedagogia, Língua Portuguesa, Matemática e Ciências Biológicas ao analisarem suas ementas, constataram que a escola, enquanto instituição social e de ensino, é elemento quase ausente nestas ementas, "o que leva a pensar numa formação de caráter mais abstrato e pouco integrado ao contexto concreto onde o profissional professor vai atuar" (Ibidem: 55).

Com relação à formação para o exercício da docência nos Anos Iniciais do Ensino Fundamental, ainda de acordo com Gatti e Nunes (2009), - a respeito da presença das disciplinas obrigatórias na composição dos currículos de 71 cursos investigados de graduação em Pedagogia no Brasil -, os conteúdos disciplinares comparecem apenas esporadicamente, na maioria sendo

\footnotetext{
${ }^{5}$ Instituídas pelo CNE/CP n ${ }^{\circ} 1$ (BRASIL, 2006), nos termos explicitados nos Pareceres CNE/CP nos 5/2005 e $3 / 2006$.
} 


\section{A LEITURA DO MUNDO E O ENSINO DE GEOGRAFIA: A DOCÊNCIA EM FOCO}

abordados de forma genérica ou superficial no interior das disciplinas de metodologias e práticas de ensino, sugerindo frágil associação com as práticas docentes.

Quanto a formação de professores nos cursos superiores de Pedagogia no tangente ao conhecimento geográfico a ser trabalhado nos AIEF, essa temática não tem sido muito pesquisada, talvez pela própria complexidade que é encontrar soluções para o problema da locação das áreas específicas durante a formação inicial (BRAGA, 2005: 231). Ao passo que, "nos cursos destinados à formação dos professores para os AIEF (Magistério e Pedagogia) não têm sido comtemplados dois aspectos fundamentais para o desempenho de suas funções: o 'o que' e 'como' ensinar Geografia" (Ibidem: 54).

Na pesquisa, A presença dos conceitos estruturadores do conhecimento geográfico nos Cursos de Pedagogia em Minas Gerais, Samara M. Silva (2017) verifica que os tempos e espaços dedicados a Geografia nos cursos de Pedagogia são ínfimos, quase que o mínimo possível (assim como as outras áreas específicas, com certa condescendência apenas com Língua Portuguesa e Matemática). Das 410 unidades curriculares catalogadas como obrigatórias nos cursos de Pedagogia, modalidade presencial, instalados nas Universidades federais em Minas Gerais, somente 18\% diziam respeito às áreas específicas que constituem o currículo dos AIEF. Destas apenas 11disciplinas regulares tratavam do conhecimento geográfico. Ainda conforme a autora, "é perceptível certo abandono das áreas específicas, em especial dos conhecimentos relativos à formação profissional peculiar ao trabalho nos AIEF no tocante ao ensino de História, Geografia, Ciências, Artes e Educação Física, e em menor 'desaceitação' de Matemática e Língua Portuguesa".

Não obstante da redução dos espaços e tempos, Silva (2017) percebeu também via análise dos Projetos Pedagógicos de Curso, Fluxograma Curricular e Ementas das disciplinas, que as categorias de análise, escalas geográficas e o próprio espaço geográfico, aparecem apenas esporadicamente nestes cursos. Pôde-se de tal modo concluir pelos dados coletados que a questão não passa apenas pela parca carga horária das unidades curriculares, mas o que é ensinado e como acontece o ensino de Geografia na formação dos professores.

Compreende-se que a necessidade de atuar com várias áreas do conhecimento limitam 0 aprofundamento das áreas específicas nos cursos de Pedagogia. E isto,

(...) torna o professor despreparado para o ensino, uma vez que o professor ensina o que sabe! Sem domínio do conteúdo que deveria ensinar, sem encantamento pelo conhecimento, sem uma cultura ampliada no campo da ciência e da arte, ele não poderá despertar nos alunos o gosto pelo saber, o entusiasmo pelo estudo (LIBÂNEO, 2010). 


\section{A LEITURA DO MUNDO E O ENSINO DE GEOGRAFIA: A DOCÊNCIA EM FOCO}

Sabe-se que essa formação não constitui integralmente a prática dos futuros professores em sala de aula, apesar de representar feitios importantes nos percursos traçados ao longo de suas carreiras.

Maurice Tardif (2000), embasado em outros autores, afirma que os saberes profissionais dos professores são temporais em três sentidos: primeiro, porque provêm de suas histórias de vida e, sobretudo de suas histórias de vida escolar; segundo, pois são nos primeiros anos de atuação que ocorre a estruturação da prática profissional, ou seja, rotina de trabalho; e por último, por serem utilizados e se desenvolverem no âmbito de uma carreira, de um processo de vida profissional de longa duração.

Com isso, os saberes profissionais dos professores provem de diversas fontes, dentre elas, sua cultura pessoal (história de vida e cultura escolar anterior), conhecimentos disciplinares adquiridos na Universidade durante sua formação profissional e também de conhecimentos curriculares veiculados pelos programas, manuais, etc. Assim como se baseia na sua própria experiência de trabalho, de colegas e em tradições peculiares (TARDIF, 2000: 14).

A respeito dos conhecimentos disciplinares adquiridos na Universidade, a Resolução que institui as Diretrizes Curriculares Nacionais para o Curso de Graduação em Pedagogia-licenciatura (DCNP) no Brasil, atesta que para a formação do licenciado em Pedagogia (dentre outros aspectos) é central o ensino de Língua Portuguesa, Matemática, Ciências, História, Geografia, Artes e Educação Física de maneira interdisciplinar e adequado às fases de desenvolvimento das crianças.

\section{Um "estranho paradoxo" na formação inicial dos professores dos AIEF?}

Entende-se que, o curso de graduação em Pedagogia, estruturado conforme pressupõe as DCNP, tem muitos e distintos objetivos a serem atingidos. Tantos que José C. Libâneo fala em um "currículo carregado de funções" e questiona: "Será possível formar esses especialistas no mesmo curso de formação de professores de 3.200 horas, como quer a ANFOPE?" (2008: 11).

Isto porque,

De acordo com as DCNP, o licenciado em Pedagogia terá como base da identidade profissional à docência nos AIEF e educação infantil. Poderá também o curso formar o pesquisador e gestor educacional para atuar na escola e em espaços não escolares, bem como na educação profissional na área de serviços e apoio escolar (BRZEZINSKI, 2008: 1160)

Os professores de áreas específicas que atuarão a partir do sexto ano do Ensino Fundamental, são formados em cursos de licenciatura exclusivos de cada área, enquanto a formação docente para 
os AIEF se dá de certa forma "aligeirada" tendo em vista os objetivos a que se propõe os cursos formadores. O que para Libâneo (2010: 581) se constitui em um "estranho paradoxo";

\begin{abstract}
Vive-se no Brasil, no âmbito da formação de docentes, um estranho paradoxo: professores dos anos iniciais do ensino fundamental, que precisam dominar conhecimentos e metodologias de conteúdos muito diferentes, como Português, Matemática, História, Geografia, Ciências e, às vezes, Artes e Educação Física, não recebem esses conteúdos específicos em sua formação, enquanto que os professores dos anos finais, preparados em licenciaturas específicas, passam quatro anos estudando uma só disciplina, aquela em que serão titulados.
\end{abstract}

Esse "estranho paradoxo" ao qual se refere Libâneo no âmbito da formação inicial de docentes traz sérios desmembramentos para o ensino de áreas específicas nos anos iniciais, o que também interfere na continuidade da escolaridade. Uma vez que, comumente ouve-se que os estudantes ingressam no sexto ano do Ensino Fundamental sem base teórica para aprenderem os conteúdos daquele ano, o que aumenta o desinteresse e dificuldades dos alunos (NOVAES, 2006).

Conforme Novaes (2006), esses fatores estão relacionados ao contato que os professores dos AIEF tiveram com o saber geográfico durante o seu processo de escolarização e de formação inicial. Portanto, caracteriza-se dois momentos distintos embora complementares: o primeiro, referente à Educação Básica e a alfabetização geográfica que deveria ter ocorrido na vida escolar destes profissionais; e o segundo, o contato insatisfatório com a Geografia na academia, no momento da formação inicial. Nas palavras de Straforini,

Sabemos que isso [papel secundário ocupado pela Geografia e por outras áreas, exceto Português e Matemática, nos ciclos iniciais do EF] decorre da falta de discussões teóricas, metodológicas e epistemológicas, bem como do grande problema na formação dos professores das séries iniciais, que assumem as suas dificuldades perante a discussão teórica das referidas disciplinas (2001: 96).

Sabe-se que é crucial para os níveis escolares seguintes a alfabetização geográfica que ocorre ou deveria ocorrer nos AIEF, uma vez que ela capacita para a leitura do mundo a partir do lugar, leitura essa tão importante para a cidadania e a vida em sociedade.

Contudo, lacunas presentes na formação docente, por vezes, contribui para o menosprezo de determinadas áreas do conhecimento nos AIEF. Bem como, para o "desserviço6" prestado por determinado tipo de ensino de Geografia na escola básica. Entretanto vale a pena ressaltar que,

\footnotetext{
${ }^{6}$ Straforini (2001: 50) apresenta a ideia de desserviço no ensino de Geografia de acordo com determinadas práticas e concepções docentes que tendem a simplificar as análises, evitando estabelecer as conexões entre local e global.
} 
É preciso, sobretudo, e aí já vai um destes saberes indispensáveis, que o formando, desde o princípio mesmo de sua experiência formadora, assumindo-se como sujeito também de produção do saber, se convença definitivamente de que ensinar não é transferir conhecimento, mas criar as possibilidades para a sua produção ou a sua construção. Se, na experiência de minha formação, que deve ser permanente, começo por aceitar que o formador é o sujeito em relação a quem me considero 0 objeto, que ele é o sujeito que me forma e eu, o objeto por ele formado, me considero como um paciente que recebe os conhecimentos- conteúdos- acumulados pelo sujeito que sabe e que são a mim transferidos (FREIRE, 1996:12, grifos do autor).

Por conseguinte, é capital que o graduando, movido pela curiosidade indagadora, crítica ou ainda, a curiosidade epistemológica de que nos fala Freire $(1985,1993)$, tenha autonomia em sua formação para potencializar e buscar novos conhecimentos. Assumindo uma postura crítico-reflexiva e não de meros receptores dos conhecimentos advindos dos docentes, até porque nenhuma unidade curricular conseguirá esgotar todo o conhecimento acumulado sobre determinada ciência/ conteúdo. Isso, por si só, exige uma postura de pesquisador que deverá acompanhá-lo, também, durante o exercício de sua profissão. Afinal, "Ensinar exige pesquisa. Não há ensino sem pesquisa e pesquisa sem ensino" (FREIRE, 1996: 14). Portanto, deve se autoformar constantemente por diferentes meios.

Entende-se, pois que a formação permanente do professor deve se tornar um hábito adquirido desde a formação inicial (graduação), ao passo que contribui para o que García (1997: 55) coloca como desenvolvimento profissional dos professores. Segundo o autor, tal noção "tem uma conotação de evolução e de continuidade que nos parece superar a tradicional justaposição entre formação inicial e aperfeiçoamento dos professores" (Ibidem).

Logo, não se pode ignorar os saberes que os docentes constroem e mobilizam no exercício de suas próprias práticas e experiências. Por conseguinte, talvez com certa redundância, reafirma-se a proficiente articulação que deve haver entre o currículo da formação inicial dos professores e seu currículo de formação permanente, ao passo que, apesar de se desenvolver ao longo de uma carreira, a formação inicial é o primeiro e um importante nível desta.

Por esse motivo, é preciso definir com clareza o que deve ser trabalhado nos cursos superiores, em especial de Pedagogia, objeto de estudo neste texto, uma vez que não é possível tratar de todos os conteúdos geográficos ou de qualquer outra área específica. Nesse sentido, Cavalcanti (2002) e Nóvoa (1997) propõem que o processo de formação de professores ocorra na perspectiva crítico-reflexiva, que lhes forneça meios de pensamento autônomo, que facilite as dinâmicas de auto formação participada e que permita a articulação teoria e prática do ensino.

Cabe considerar, por conseguinte, que sendo os lugares carregados de historicidade e espacialmente delimitados, são altamente complexos e dinâmicos (CALLAI, 2005) e, portanto, 


\section{A LEITURA DO MUNDO E O ENSINO DE GEOGRAFIA: A DOCÊNCIA EM FOCO}

encerram em si especificidades da vida dos homens em sua cotidianidade, mas também a homogeneidade do global. "Repensar a relação entre local e mundial, torna-se, portanto, tarefa fundamental para entender o mundo moderno" (CARLOS, 2007: 11), e, consequentemente, para o ensino contextualizado de Geografia em todos os níveis da Educação Básica.

Enfim, toda compreensão de algo corresponde cedo ou tarde, a uma ação, e esta corresponde à natureza da compreensão (FREIRE, 2014: 138-139). Assim, será tão mais crítica quanto maior a conscientização que embasa a práxis, e tanto mais ingênua/mágica quanto menor a organização reflexiva de captura da realidade. $E$ isto vale se falamos de crianças nos AIEF, de graduandos dos cursos superiores ou de docentes que através de suas práticas intervêm no mundo.

Dessa forma, as universidades e, por conseguinte, os cursos de licenciatura, devem contribuir para a formação inicial e continuada dos professores da Educação Básica. Entende-se que a aproximação entre esses dois espaços constitui uma via de mão dupla que possibilita a construção de novos saberes e, consequentemente, a melhoria da qualidade do ensino em ambos.

\section{Considerações Finais}

A relação entre leitura da palavra-mundo e a compreensão do espaço geográfico pode se constituir em um ponto de encontro entre a alfabetização e o ensino de Geografia durante os AIEF. Consequentemente, entender como ocorre a produção do espaço local (vivido), aliada a perspectiva histórica e social do contexto de outras escalas de análise, contribui para a consciência de sujeito ativo nos processos de (re) construção da realidade e do espaço, que é local e global.

Não se desconsidera, conforme Tardif (2000), que ao se pensar os saberes docentes presentes nas salas de aula é imprescindível ponderar, além da formação inicial recebida pelos professores nas instituições de ensino superior, suas próprias práticas e conhecimentos desenvolvidos, o saber-fazer próprio de um sujeito também ativo no processo de ensino e aprendizagem.

Sem desprezar os fatores do "saber plural" dos docentes, apontado por Tardif, entende-se que a formação inicial pode contribuir para a definição dos percursos traçados pelos professores ao longo de sua carreira e que de certa forma, afeta e condiciona o ensino de Geografia nos AIEF.

Portanto, é necessário repensar o modelo de ensino nos cursos de Pedagogia, licenciatura que, ao destinar poucos momentos para a construção dos conceitos estruturadores, linguagens, métodos e práticas que envolvem o ensino de Geografia, podem comprometer a aptidão dos egressos desses cursos para exercerem seu trabalho nos AIEF.

Conclui-se que, ao pensarem criticamente o espaço em que vivem, mediatizados pelo conhecimento geográfico, os professores dos Anos Iniciais do Ensino Fundamental, promoverão com 


\section{A LEITURA DO MUNDO E O ENSINO DE GEOGRAFIA: A DOCÊNCIA EM FOCO}

maior autonomia e clareza um ensino mais significativo e interdisciplinar nessa etapa da Educação Básica. Enfim, capazes de favorecer nesse momento de iniciação escolar, a construção de conhecimentos mediados pelo mundo em função da leitura da palavra e/ou vice-versa, com a clareza de que a construção do conhecimento, nessa faixa etária da aprendizagem (AIEF), se concretiza com respeito aos alunos, suas leituras de mundo e conhecimentos prévios, fruto de suas experiências em seus espaço de vivência.

\section{Referências}

BRAGA, Maria Cleonice Barbosa. Aprender e ensinar Geografia: a visão de egressos do Curso de Pedagogia da UEFS (Universidade Estadual de Feira de Santana) / Tese (Doutorado). Universidade Federal de São Carlos, 2006. São Carlos: UFSCar, 2006. 251 p.

BRASIL. CONSELHO NACIONAL DE EDUCAÇÃO. Resolução 1/2006. Institui Diretrizes Curriculares Nacionais para o Curso de Graduação em Pedagogia licenciatura. Maio de 2006.

Secretaria de Educação Fundamental. Parâmetros curriculares nacionais: História, Geografia. Vol.5. Brasília: MEC/SEF, 1997.

Lei Federal $n^{\circ}$ 9.394, de 20 de dezembro de 1996. Estabelece as Diretrizes e Bases da Educação Nacional. Disponível em: (http://www.planalto.gov.br/CCIVIL/LEIS/I9394.htm). Acesso em: 30 de setembro de 2015.

BRZEZINSKI, Iria. Políticas Contemporâneas de Formação de professores para os Anos Iniciais do Ensino Fundamental. Educ. Soc., Campinas, vol. 29, n. 105, p. 1139-1166, set./dez. 2008. Disponível em: (http://www.cedes.unicamp.br). Acesso em 03 de dezembro de 2015.

CALLAl, Helena Copetti. 0 município: uma abordagem geográfica nos primeiros anos da formação básica. In: CAVALCANTI, Lana de Souza. Temas da Geografia na escola básica. Campinas, SP: Papirus, 2013.

A Geografia Escolar - e os conteúdos da Geografia. Revista Anekumene · Geografía, Cultura Y Educación. Revista Virtual. N.1. 2011. p. 128-139.

Aprendendo a ler o mundo: a Geografia nos anos iniciais do Ensino Fundamental. Cad. Cede, Campinas, vol. 25, n. 66, p. 227-247, maio/ago. 2005. Disponível em (http://www.cedes.unicamp.br\&gt); Acesso 28 de junho de 2010.

Estudar o lugar para compreender o mundo. In: CASTROGIOVANNI, Antônio Carlos. (org). Ensino de Geografia: práticas e textualizações no cotidiano. $7^{\mathrm{a}}$ ed. Porto Alegre: Mediação, 2000, p. 83-131.

CARLOS, Ana Fani Alessandri. O lugar no/do mundo. São Paulo: FFLCH, 2007. 85 p. 
CASTROGIOVANNI, Antônio Carlos. (Org.). Ensino de Geografia: práticas e textualizações no cotidiano. 7. ed. Porto Alegre: Mediação, 2009.

FREIRE, Paulo. Educação e Conscientização. In: FREIRE, Paulo. Educação como prática da Liberdade. 36. ed. São Paulo: Paz e Terra, 2014. p. 133-189.

Educação e atualidade brasileira. São Paulo: Cortez, 2003.

Pedagogia dos sonhos possíveis. In: ARAÚJO, Ana Maria (Org.). Pedagogia dos sonhos possíveis. São Paulo: Unesp, 2001.

Pedagogia da autonomia: saberes necessários à prática educativa. São Paulo: Paz e

Terra, 1996.

1993.

Professora, sim; tia não: cartas a quem ousa ensinar. São Paulo: Olhos D'água,

Pedagogia da esperança: um reencontro com a Pedagogia do oprimido. Rio de Janeiro: Paz e Terra, 1992.

A importância do ato de ler: em três artigos que se completam. 23 ed. São Paulo:

Cortez, 1989.

; FAUDEZ, Antônio. Por uma pedagogia da pergunta. Rio de Janeiro: Paz e Terra, 1985.

GARCÍA, Carlos Marcelo. A formação de professores: novas perspectivas baseadas na investigação sobre o pensamento do professor. In: NÓVOA, António (Coord.). Os professores e a sua formação. 3. ed. Lisboa: Publicações Dom Quixote, 1997. p. 51-76.

GATTI, Bernardete A; NUNES, Marina Muniz R. (orgs.). Formação de professores para o ensino fundamental: estudo de currículos das licenciaturas em pedagogia, língua portuguesa, matemática e ciências biológicas. São Paulo: FCC/DPE, 2009.

LEÃO, Vicente de Paula. A influência das Diretrizes Curriculares Nacionais do Ministério da Educação e Cultura para a Formação de Professores de Geografia da Educação Básica em Nível Superior. 2008. 121 f. Tese (Doutorado em Geografia) -Programa de Pós-graduação, Departamento de Geografia, Universidade Federal de Minas Gerais, Belo Horizonte, 2008.

LE SANN, J. G.; VALADÃO, R. C. Relatório final de atividade do CAP - GEOGRAFIA. Belo Horizonte: UBBE, 2003.

LIBÂNEO, J. C. O ensino da Didática, das metodologias específicas e dos conteúdos específicos do ensino fundamental nos currículos dos cursos de Pedagogia. Revista Brasileira de Estudos Pedagógicos. Brasília, v. 91, n. 229, p. 562-583, set./dez. 2010.

Pedagogia e Pedagogos, para quê? 10.ed. São Paulo: Cortez, 2008. 
NOVAES, Ínia Franco de. A geografia nas séries iniciais do ensino fundamental: desafios da e para a formação docente. Dissertação (mestrado) - Universidade Federal de Uberlândia, Programa de PósGraduação em Geografia. 2006. 202 f.

NÓVOA, António (Coord.). Os professores e a sua formação. 3. ed. Lisboa: Dom Quixote, 1997. 158 p.

SILVA, Samara Mirelly da.; LEAO, Vicente de Paula. Anos Iniciais do Ensino Fundamental: Por onde anda a Geografia?. Caderno de Geografia PUC Minas, v. 26, p. 382-395, 2016. Disponivel em: (http://periodicos.pucminas.br/index.php/geografia/article/view/P.2318-2962.2016v26n46p382) Acesso em 09 de julho de 2017.

A Presença dos conceitos estruturadores do Conhecimento Geográfico nos Cursos de Pedagogia em Minas Gerais. São João del-Rei, 2017, 150 p. Dissertação (Mestrado) Programa de Pós Graduação em Geografia - Universidade Federal de São João del-Rei, 2017.

STRAFORINI, R. Ensinar geografia nas séries iniciais: o desafio da totalidade mundo. Dissertação (Mestrado) - Instituto de Geociências, Universidade Estadual de Campinas, Campinas, 2001. $155 f$.

TARDIF, Maurice. Saberes profissionais dos professores e conhecimentos universitários/ Elementos para uma epistemologia da prática profissional dos professores e suas consequências em relação à formação para o magistério. Revista Brasileira de Educação, n 13, 2000. 